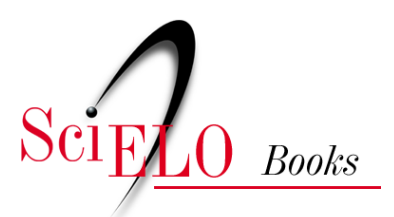

\title{
6. Tensionarte-trazos de Wbeimar
}

\author{
César Augusto Tapias Hernández
}

\section{SciELO Books / SciELO Livros / SciELO Libros}

TAPIAS HERNÁNDEZ, C.A. Tensionarte-trazos de Wbeimar. In: Historias de familia: Etnografía delirante sobre el amor, la violencia y las drogas [online]. Bogotá: Editorial Universidad del Rosario, 2014, pp. 25-28. Textos de ciencias humanas collection. ISBN: 978-958-738-543-4.

https://doi.org/10.7476/9789587385434.0007.

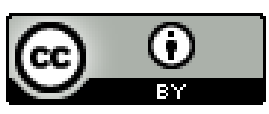

All the contents of this work, except where otherwise noted, is licensed under a Creative Commons Attribution 4.0 International license.

Todo o conteúdo deste trabalho, exceto quando houver ressalva, é publicado sob a licença Creative Commons Atribição 4.0.

Todo el contenido de esta obra, excepto donde se indique lo contrario, está bajo licencia de la licencia $\underline{\text { Creative }}$ Commons Reconocimento 4.0 . 


\section{Tensionarte-trazos de Wbeimar}

¿De qué sirve polemizar con la nada? Ya es hora de serenarnos, de triunfar sobre la fascinación de lo peor. No todo está perdido.

Emil M. Cioran, La tentación de existir

Hombre de cabello negro, como de indio. De faz alargada y bien delineada. Tus chaquetas y botas... Tus ojos. Tus manos muchas veces ocultas, pero victoriosas. ¡Hay cosas que la muerte no se lleva! El ángel guerrero, el de espada gigante, va montado en su unicornio de músculos fuertes y patotas grandes. Demonios de cuernos largos y con barbas muy negras reciben rayos que matan: deseo de vida aniquilado por la maldad... En la sala de donde Efigenia, un cuadro de Wbeimar parece consagrar al amor una falsa victoria sobre la maldad...

Wbeimar era el menor del matrimonio entre el también difunto tío Gilberto, y la muy joven aún Efigenia. Los otros dos hijos son Claudia y Fredy. Hace un par de meses el primo Wbeimar fue asesinado de la manera más absurda y, por desgracia, también la más común. En los barrios populares y despojados de cualquier realidad nacional como el tropel ente "paras" y guerrilleros", nos matamos de a poco para controlar unas cuadras, y mostrar un poderío ínfimo pero devastador, hablando al mundo de un honor estúpido... Honor fundamentado en miradas frías y vacías, que con palabras secas y disparos certeros ordena el mundo al amaño de unos pocos...

Así, cualquier humano que en medio de la noche se sienta dueño hasta de la noche misma, puede desenfundar su arma y disparar... seguro de que el caído era una gonorrea del otro combo... pero seguridad nunca puede haber...

Wbeimar se fue así, porque otro lo decidió. Y se quedaron inconclusos muchos de sus trazos: mujeres desnudas rodeadas por demonios; un paisaje para Efigenia, una rubia de ojos cafés fumándose un puro, objetos y formas expuestas a la luz y su firma, una W (doble u) sostenida entre tensiones que se contraen, a la manera de 
fuerzas encontradas que van chocando unas contra otras, dando forma a algo, a él mismo... A él y su arte.

El primo Wbeimar era para muchos un ser extraño. Una vez Efigenia comentó que hasta desconocido por algunos en la misma cuadra...

—Un día resultó metido en todo aquello del rock — cuenta su hermano Fredy - con amigos artistas y artesanos también, y se parchaba mucho en el Parque del Periodista, y dibujaba cosas extrañas que bien le podrían costar la excomunión... Su círculo de amigos eran puros hombres... Yo sí preferí la salsa, y las niñas... Otra rumba, entonces ya grandecitos todo fue un choque entre ambos. Terminamos hablándonos lo necesario.

Y la vida es así: termina uno por hallarle el sentido cuando todo ha terminado. Como si la muerte fuese necesaria... Pier Paolo Pasolini (1971) tiene un ensayo hermosísimo sobre eso... "Es absolutamente necesario morir — dice- porque, mientras estamos vivos, carecemos de sentido...”.

Fredy reconoce que, a la final, los roces que tuvieron fueron cosas sin importancia, Wbeimar le cogía sus cosas, y eso al Fredy no le molestaba, siempre y cuando las cosas volvieran a estar en su lugar, y eso era lo que no sucedía. Quizás la pelea última haya sido por un encendedor... Esa historia de disputas y pocas palabras, se parece a la de mi hermano y yo... Nosotros también terminamos hablándonos apenas lo necesario. Triste.

Mientras Fredy terminaba de vestirse para ir en busca de unas cervezas, yo lo esperaba en la sala de su casa viendo ese cuadro de Wbeimar: pintura llena de azules y naranjas... Vi también la placa que acreditaba su talento en la pintura y un par de fotos suyas en el diploma del colegio y el certificado de un concurso donde estuvo Wbeimar cuando era un pelaíto al que ya se le notaba la fibra de artista... Sonaba salsa romántica con un sonido espacial, un poco brillante el acorde de coros sobre los ritmos también brillantes. Era un equipo de sonido viejo, una grabadora de disco compacto y par de parlantes como monstruos negros a los lados....

- Hey, Fredy, ¿qué es lo que tenés aquí montado?

-El equipo funcionando como un amplificador — responde Fredy- Al equipo llega la grabadora, dos parlantes de 300 watts cada uno y tres twitters... ¡Mero sonido!, ¿no?

De lo que se trata, para que entiendan, es de un equipo de sonido Motorola que tienen en esta casa desde hace unos veintiséis años, los que de casados según Efigenia. El equipo tenía una entrada y una salida para los bafles, dos superparlantes que bien podrían amplificar una orquesta en vivo, los twitters según percibo, dan el brillo 
ese tan notorio. Ya me gustaría escuchar de ese modo, bien duro y bien brillante la mejor pieza de SALSA: "Vámonos pa'l monte”, de Eddie Palmieri (versión en vivo). Pensé en decírselo al primo, pero como que lo sospechó, desde un principio y me fue repitiendo que el equipo ese no funcionaba, sino como amplificador, ni radio, ni tornamesa... Qué falla pensé yo.

El primo Fredy cursa actualmente el tercer semestre de Trabajo Social en la Universidad de Antioquia. Preferiría él estudiar ingeniería de sistemas, pero no se apura. Hoy le interesa el trabajo social, y saber eso ya es bastante. Piensa en la ventaja de la interdisciplinariedad de su carrera, por cuanto debe coger algo de las demás ciencias sociales...

—Eso está bien — afirma el primo-. Necesitaríamos de un nuevo Freud en la universidad que establezca esto como ciencia y lo pruebe de una forma tal que las demás ciencias no nos hagan falta.

Y más allá de todo eso, le complace ver a mi primo que el nuevo perfil del trabajador social es mucho más intervencionista ahora:

-Antes era puro asistencialismo y uno estaba en los hospitales para rebajarles la cuenta a los pacientes de bajos recursos. Hoy puede ser uno el líder, el que convoque o impulse el trabajo de un grupo o comunidad; se trata de hacer, de estar metido en la formulación de los proyectos, vamos a ver... Ojalá.

Y, más allá, el primo dice que eso de las humanidades le favorece a uno en lo personal, pues tiene uno que hablar más y decir qué es lo que está pensando, que dizque adquiere uno más conciencia... Dice él.

-Qué iba yo a saber qué era el capitalismo o el socialismo... Es en la universidad donde se da uno cuenta del mundo y después ves las noticias hasta distinto...

Dos años hace que murió el tío Gilberto. A mí, por lo menos, siempre me pareció un tipo lejano, como Wbeimar, silencioso. Sin embargo, era especial... Como al tío Gildardo, le gustaba tener el cabello largo; pero era muy malgeniado y eso desesperaba a todos, aun cuando nunca se metió con nadie. Y Fredy, otra vez como cualquier ser humano, haya el sentido de la vida del tío, ida ya la vida del tío...

- Cómo no iba a estar malgeniado mi papá con ese trabajo...

- ¿Qué hacía, pues, el tío?

- Trabajar en la construcción. Pero había días en que se le notaba contento, era cuando le caían trabajos de electricidad...

Fredy tiene pinta de cachivachero o marañero; eso se lo aprendió al tío Gilberto. De niño, pillaba mi primo cómo el tío desbarataba y armaba electrodomésticos, y lo acompañaba algunas veces, a regañadientes, a las casas donde el tío tenía que 
arreglar la luz... Hoy, Fredy desbarata una moto y vuelve y la monta de nuevo. Así como pillaba al cucho camellando, pillaba al mecánico y entonces esas cosas por la que pagaba ya las hace él...

-Primo, y ¿tú mamá...?

- Mi mamá es puro amor. Navega en un mar de ingenuidad y entonces cualquiera se la convence, pero es de puro amor por los demás...

-Y ¿Claudia?

-Mi hermanita es muy inteligente, pero muy elevada, hermano...

-Dispersa podría ser la palabra apropiada... ¿No crees?

- Podría ser...

Del primo Fredy podría decir yo que es un tipo abierto al mundo. La U le pegó donde era y seguro le pegará todavía más. De esos golpes son los que uno necesita... Y aspira él, sin afán, estudiar sistemas, electricidad o electrónica... Y en cuanto al trabajo social, le gustaría irse más bien por el lado de las organizaciones, los conflictos en las empresas y todo aquello. Le teme un poco a la tesis, pero yo le digo que eso es hasta bacano, la confrontación siempre es necesaria... y gratificante después de todo... Así parecen levantarse los trazos del desaparecido primo Wbeimar: tensiones que se contraen. Y nos es que yo me lo haya inventado ya, no. Entre los bocetos del primo está el borrador de su firma: las curvas que conforman sus líneas tienen flechas que se encuentran, y con letras pequeñitas, el primo escribió muchas veces la palabra tensión...

Tensión debió haber entre ellos dos: Wbeimar y Fredy... Tensión la que dejó el Wbeimar como regalada a su hija, una nena que con mínimos años ya raya los cuadernos haciendo "píos", tensión su mismo arte falleciendo ante el arma implacable del hombre que le disparó sin preguntar... Tensión aún tensa en sus obras inconclusas... Quien quita que hasta su niña un día las termine... Tensión era el mismo Wbeimar... Hombre de cabello negro, como de indio. 